\title{
The Chronically Reserpinized Rat as a Model for Cystic Fibrosis: Alterations in Pancreatic Enzyme Secretion and Storage
}

\author{
RUTH E. MCCURDY AND RICARDO MARTINEZ ${ }^{(17)}$ \\ Department of Child Health, University of Missouri School of Medicine, Columbia Missouri, USA
}

\begin{abstract}
Summary
Alterations in the pancreatic secretion of fluid and of enzymes in response to either pilocarpine $(15 \mathrm{mg} / \mathrm{kg})$ or an octapeptide of cholecystokinin $(0.1 \mu \mathrm{g} / \mathrm{kg})$ have been found in rats that received daily injections of reserpine $(0.5 \mathrm{mg} / \mathrm{kg})$ for 7 days. During a 3-hr secretory period, significant reductions in the volume of pancreatic juice and in the total output of protein, amylase, and trypsin were observed in these animals. In the first hour of the secretory response, however, protease output was increased in the treated animals, particularly that of chymotrypsin, which was also increased in the longer secretory period following pilocarpine, but not cholecystokinin, stimulation. Zymogen granules isolated from the pancreas of the treated rats by differential centrifugation in a $0.3 \mathrm{M}$ sucrose buffer had increased specific activities of the proteases when compared to those of untreated controls. Ultrastructurally, zymogen granules isolated from the pancreas of the treated rats showed changes in density, with bizonal and trizonal configurations being frequently observed, and had less distinct limiting membranes. In some, the membrane appeared broken at intervals, and there was granular material, presumably derived from the granule contents, lining the surface of the granule. It is concluded that pretreatment with reserpine inhibits fluid secretion and alters enzyme secretion in the rat exocrine pancreas. The latter effect is related to a nonparallel storage of amylase and proteases in the secretory granules induced by the drug treatment, probably through an action on protein synthesis or intracellular transport. An accumulation of proteases may lead to activation of these enzymes and to granule lysis. Inasmuch as the reserpinetreated rat has been proposed as an experimental model for cystic fibrosis, these findings are relevant in terms of possible pathogenetic mechanisms in this disease.
\end{abstract}

\section{Speculation}

The chronic administration of reserpine to rats causes an increased storage and secretion of proteases, particularly chymotrypsin, in the exocrine pancreas. This may lead to intracellular activation of these enzymes and to alterations in exocrine pancreatic structure and function. Inasmuch as pretreatment with reserpine also causes alterations in fluid and bicarbonate secretion similar to those seen in cystic fibrosis, the effects on pancreatic enzymes suggest a mechanism for the pathogenesis of the exocrine pancreatic disturbance in this disease.

The exocrine pancreas of rats treated in a chronic fashion with reserpine shows ultrastructural and secretory abnormalities which suggest a drug effect on both acinar and ductal segments of the glandular epithelium (10-12). An accumulation of acinar secretory granules, a reduction in rough endoplasmic reticulum, and changes in Golgi membranes are found in the resting gland (12). Granule discharge is reduced upon stimulation with cholecystokinin and is accompanied by the appearance of numerous auto- phagic bodies (12). The secretory response to both hormonal and neurohumoral stimulation is, furthermore, altered and characterized by reductions in the volume of pancreatic juice and in the output of bicarbonate and of amylase $(10,11)$.

These observations suggested the need for a more detailed study of the effects of pretreatment with reserpine on digestive enzyme secretion from the exocrine pancreas. In this investigation, therefore, a comparative analysis of the in vivo secretion of amylase, trypsin, and chymotrypsin from the pancreas of reserpine-treated rats and of untreated controls has been carried out in conjunction with a study of the ultrastructure and of the content of these enzymes in pancreatic zymogen granules isolated before and after stimulation with pilocarpine and with cholecystokinin. Inasmuch as the reserpine-treated rat has been proposed as an experimental animal model for cystic fibrosis on the basis of several exocrine gland alterations $(5-8,11,13,14)$, this study constitutes an attempt to investigate possible pathogenetic mechanisms in the pancreatic lesion of this model that may have relevance to the human disease.

\section{MATERIALS AND METHODS}

Adult male rats of the Sprague Dawley strain were used. A number of animals (see "Results") were treated with seven daily doses of reserpine $(0.5 \mathrm{mg} / \mathrm{kg}$ body weight IP), and matched ones were used as untreated controls. Both groups of rats were housed in the same quarters and had free access to water and to a standard pelleted diet. Food, but not water, was removed for the last $24 \mathrm{hr}$ before the experiment. Two types of experiments were performed: (1) the collection of pancreatic juice after stimulation with appropriate secretagogues for the analysis of enzyme secretion; and (2) the isolation and analysis of the enzyme content of zymogen granules obtained from both unstimulated and stimulated tissue.

In the first case, the rats were anesthetized with sodium pentobarbital ( 6 to $8 \mathrm{mg} / \mathrm{kg}$ body weight IP) and the trachea, the external jugular vein, and the common bile duct were cannulated as previously described $(10,11)$. The pancreatic duct was cannulated with a polyethylene cannula (Clay Adams PE10) inserted for a short distance into its duodenal end. Ligatures were tied around the hepatic end of the duct to prevent contamination with bile, as previously described $(10,11)$. The animals were kept in a heated operating table to maintain body temperature and either a single IV injection of pilocarpine nitrate $(15 \mathrm{mg} / \mathrm{kg}$ body weight) or an IV infusion of cholecystokinin octapeptide $(0.1 \mu \mathrm{g} / \mathrm{kg})$ was administered. These doses have been previously found to cause adequate secretory responses from the rat pancreas $(10,11)$. Samples of pancreatic juice were collected at timed intervals for periods of 1 to $3 \mathrm{hr}$ in preweighed plastic microsample tubes kept in ice. At the end of the collection period, the animals were killed by exsanguination through the abdominal aorta, and the pancreas was removed and homogenized as described below. The collection tubes were reweighed to obtain a gravimetric estimate of the volume of pancreatic juice secreted, and each sample was then analyzed for enzyme content as follows: (1) for amylase, a 1 or 2 $\mu l$ aliquot was diluted in ice-cold distilled water and analyzed with 
the Harleco reagent kit. This is a colorimetric method that compares the differences in absorbance of a starch-iodine complex in the presence and absence of the sample. A unit of amylase is defined as the amount that hydrolyzes $10 \mathrm{mg}$ of starch at $26^{\circ} \mathrm{C}$ in $10 \mathrm{~min}$; (2) for trypsin, a 5 to $10 \mu \mathrm{l}$ aliquot of juice was incubated for $30 \mathrm{~min}$ at $37^{\circ} \mathrm{C}$ in the presence of $0.5 \mathrm{ml}$ enterokinase (Sigma E8 128; $40 \mathrm{mg} / 100 \mathrm{ml}$ buffer) and of $1 \mathrm{ml}$ of buffer [0.046 M Tris containing $\left.0.0115 \mathrm{M} \mathrm{CaCl}_{2}(\mathrm{pH} 8.1)\right]$. A $0.1 \mathrm{ml}$ aliquot of the incubation mixture was then used for the measurement of trypsin activity. For this purpose, the rate of hydrolysis of $p$-toluene sulfonyl-L-arginine methyl ester (TAME) is measured by the increase in absorbancy at $247 \mathrm{~m} \mu$. One unit of enzyme activity is equal to the hydrolysis of one micromole of TAME per minute at $25^{\circ} \mathrm{C}$ and $\mathrm{pH} 8.1$ in the presence of $0.01 \mathrm{M}$ calcium ion. The 0.1 $\mathrm{ml}$ aliquot of enterokinase-activated sample is mixed with $0.3 \mathrm{ml}$ of $0.01 \mathrm{M}$ TAME and $2.6 \mathrm{ml}$ of Tris buffer $(0.046 \mathrm{M}$; $\mathrm{pH} 8.1)$ containing $0.0115 \mathrm{M} \mathrm{CaCl}_{2}$, and absorbancy is recorded every 30 $\mathrm{sec}$ for $5 \mathrm{~min}$ and plotted against time. $\Delta \mathrm{A} / \mathrm{min}$ is determined from the straight portion of the slope. A blank containing $0.1 \mathrm{ml}$ of $0.001 \mathrm{M} \mathrm{HCl}$ instead of the sample, plus the substrate and buffer, is used to zero the spectrophotometer; (3) chymotrypsin activity was measured in $0.1 \mathrm{ml}$ aliquots of the enterokinaseactivated pancreatic juice by establishing the rate of hydrolysis of benzoyl-L-tyrosine ethyl ester. The change in absorbancy at 256 $\mathrm{m} \mu$ is determined in a mixture that contains the sample, $1.4 \mathrm{ml}$ of benzoyl-L-tyrosine ethyl ester substrate, $(0.00107 \mathrm{M}$ in $50 \%$ methanol) and $1.5 \mathrm{ml}$ of $0.08 \mathrm{M}$ Tris buffer ( $\mathrm{pH} 7.8$ ) containing $0.1 \mathrm{M}$ $\mathrm{CaCl}_{2}$. A unit is equivalent to $1 \mu$ mole of substrate hydrolyzed per minute at $\mathrm{pH} 7.8$ and $25^{\circ} \mathrm{C}$. An appropriate blank containing 0.1 $\mathrm{ml}$ of $0.001 \mathrm{M} \mathrm{HCl}$ instead of the sample is used to zero the instrument, and $\Delta \mathrm{A}$ is calculated for a 4 to $5 \mathrm{~min}$ period as indicated above. These measurements were made in a Beckman DU spectrophotometer with a Gilford Instruments attachment and recorder.

The second type of experiment involved the isolation of zymogen granules in resting tissue and following stimulation with secretagogues. This was carried out according to the method of Meldolesi et al. (9), with some modifications. The pancreas was trimmed, minced, and homogenized in 10 volumes (w/v) of $0.3 \mathrm{M}$ sucrose using 20 strokes of a Teflon-glass homogenizer. Six ml samples of this homogenate were centrifuged at $1000 \times \mathrm{g}$ for 12 $\min$ in a Sorvall centrifuge kept in a refrigerated room. The supernatant was aspirated, the pellets were resuspended in $5 \mathrm{ml}$ of $0.3 \mathrm{M}$ sucrose, and the suspension was centrifuged at $180 \times \mathrm{g}$ for 12 min to sediment cell debris, red cells, nuclei, and plasma membranes. The resulting supernatant was removed with a Pasteur pipette, filtered through a nylon mesh, and centrifuged at $1000 \times g$ for $3.5 \mathrm{~min}$ to yield a tightly packed white pellet of zymogen granules covered by a loose tan layer rich in mitochondria. This layer was removed by swirling. In some experiments, the $0.3 \mathrm{M}$ sucrose was removed, and cold, 3\% cacodylate-buffered gluteraldehyde was slowly added to the tubes with care taken not to disturb the pellet. The pellets were fixed for 18 to $24 \mathrm{hr}$ at $4^{\circ} \mathrm{C}$, washed twice in cold $0.1 \mathrm{M}$ cacodylate (7.5\% sucrose buffer), postfixed in $1 \%$ osmium tetraoxide in Millonig's phosphate for 1 $\mathrm{hr}$ at room temperature, and washed twice in buffer. Dehydration was done in a graded series of ethanols, the ethanol was exchanged twice with $100 \%$ propylene oxide, and the material was infiltrated with mixtures of propylene oxide and Luft's Epon 812, either for $2 \mathrm{hr}$ or overnight. The pellet was embedded in $100 \%$ Epon 812 and stained for $1 \mathrm{~min}$ with uranyl acetate and for $1.5 \mathrm{~min}$ with lead citrate.

To extract granule contents, the pellets obtained in other experiments were resuspended in $1 \mathrm{ml}$ of $0.2 \mathrm{M}$ Tris- $\mathrm{HCl}$ buffer $(\mathrm{pH}$ 7.8), and the suspension was immediately centrifuged for $30 \mathrm{~min}$ at $550 \times \mathrm{g}$. The resulting pellet contained zymogen granule membranes, some unextracted granules, and mitochondria, whereas the supernatant contained the digestive enzymes. Aliquots of the supernatant were used for amylase determinations with the method indicated above for pancreatic juice. These aliquots (10 $\mu l)$ were diluted with distilled water. Other aliquots were treated with enterokinase and then used for the determination of trypsin and chymotrypsin.

For trypsin, a $200 \mu \mathrm{l}$ aliquot of sample was incubated for 30 min at $37^{\circ} \mathrm{C}$ in the presence of $0.5 \mathrm{ml}$ of enterokinase (see above) and $0.8 \mathrm{ml}$ of Tris buffer $\left[0.046 \mathrm{M}\right.$ Tris containing $0.0115 \mathrm{M} \mathrm{CaCl}_{2}$ $(\mathrm{pH} 8.1)]$. A $0.1 \mathrm{ml}$ aliquot of the incubation mixture was then used for the measurement of trypsin activity as described above. For chymotrypsin, a $100 \mu \mathrm{l}$ aliquot of supernatant from the lysed granules was incubated for $30 \mathrm{~min}$ at $37^{\circ} \mathrm{C}$ in the presence of 0.5 $\mathrm{ml}$ enterokinase and $0.9 \mathrm{ml}$ of Tris buffer $[0.08 \mathrm{M}$ Tris containing $0.1 \mathrm{M} \mathrm{CaCl}_{2}$ (pH 7.8)]. A $0.1 \mathrm{ml}$ of this was used for the determination of chymotrypsin activity as described before. Protein concentrations in pancreatic juice samples and in the granule content supernatant were measured by the Lowry method (4).

Several variables were explored to determine the conditions for optimal activation of the pancreatic enzymes, particularly of the proteases. Maximum activation time was examined by varying the incubation time of the samples with enterokinase from 30 to 90 min. In other experiments, two concentrations of enterokinase were used $(40$ and $400 \mathrm{mg} / \mathrm{ml})$ in 30 -min incubations. The effect of adding albumin to the incubation buffer was also investigated. For this purpose, $100 \mu \mathrm{g} / \mathrm{ml}$ of bovine serum albumin was added to the incubation tubes. The results presented are those obtained under the optimal conditions determined with these experiments.

The following drugs and reagents were used: (1) pilocarpine nitrate, from the Sigma Chemical Company, St. Louis, MO; (2) a synthetic octapeptide of cholecystokinin was the gift from E. Squibb Pharmaceutical Company.

\section{RESULTS}

\section{PANCREATIC JUICE}

In general, rats treated with reserpine secreted smaller volumes of pancreatic juice than did control rats after stimulation with either pilocarpine or CCK-octapeptide. The reduction in volume amounted to $\approx 29 \%$ in the case of pilocarpine and to $26 \%$ in the case of CCK octapeptide. These results confirm previous observations $(10,11)$.

The specific activities of amylase, trypsin and chymotrypsin in the pancreatic juice collected from control and reserpine treated rats are plotted in Figures 1 and 2 which illustrate, respectively, typical experiments after pilocarpine and CCK stimulation. It can be seen that in both cases the specific activity of amylase was reduced, and those of trypsin and chymotrypsin were increased in the pancreatic juice of reserpine-treated rats. The total output of protein and of the three enzymes in the juice of the two groups of animals is summarized in Table 1 , which presents data relative to two collection times ( 1 and $3 \mathrm{hr}$ ) after stimulation with pilocarpine and with the octapeptide of CCK. During a timed 60 -min response, the reserpine-treated rats had a larger output of protein, which was essentially due to a larger output of chymotrypsin and, to a lesser extent, of trypsin. By contrast, the output of amylase was essentially similar to that of control animals (Table 1). When the output of the three enzymes and of protein was measured during a 3-hr secretory response, the reserpine-treated animals showed a reduced protein output, as a result of a decreased output of both amylase and trypsin (Table 1). The output of chymotrypsin, however, was still higher in the juice of the treated animals during a 3-hr collection of pancreatic juice (Table 1).

\section{ISOLATED ZYMOGEN GRANULES-ENZYME CONTENT}

The specific activities of the three enzymes in zymogen granules isolated from the resting and stimulated pancreas of control and reserpine-treated rats are summarized in Table 2 . In the resting (unstimulated) state, zymogen granules isolated from the tissue of reserpine-treated rats had a significantly higher chymotrypsin specific activity. That of trypsin was also higher than in control granules, but not to the extent observed with chymotrypsin (Table 2 ). One hr after stimulation with pilocarpine, the specific activities 

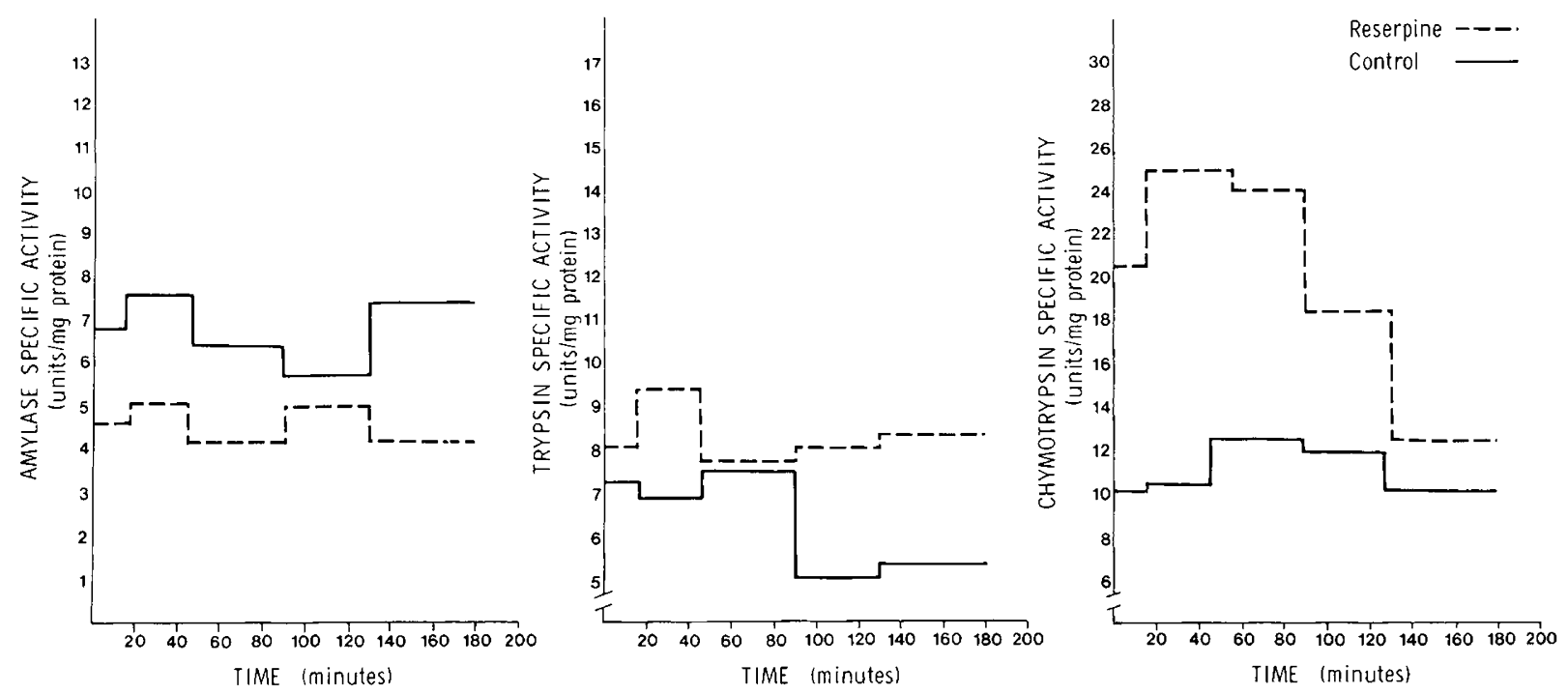

Fig. 1. Specific activities of amylase, trypsin, and chymotrypsin in the pancreatic juice of control and reserpine-treated rats after stimulation with pilocarpine ( $15 \mathrm{mg} / \mathrm{kg}$ body weight $\mathrm{IV})$. This figure illustrates a typical experiment from a group of similar protocols.
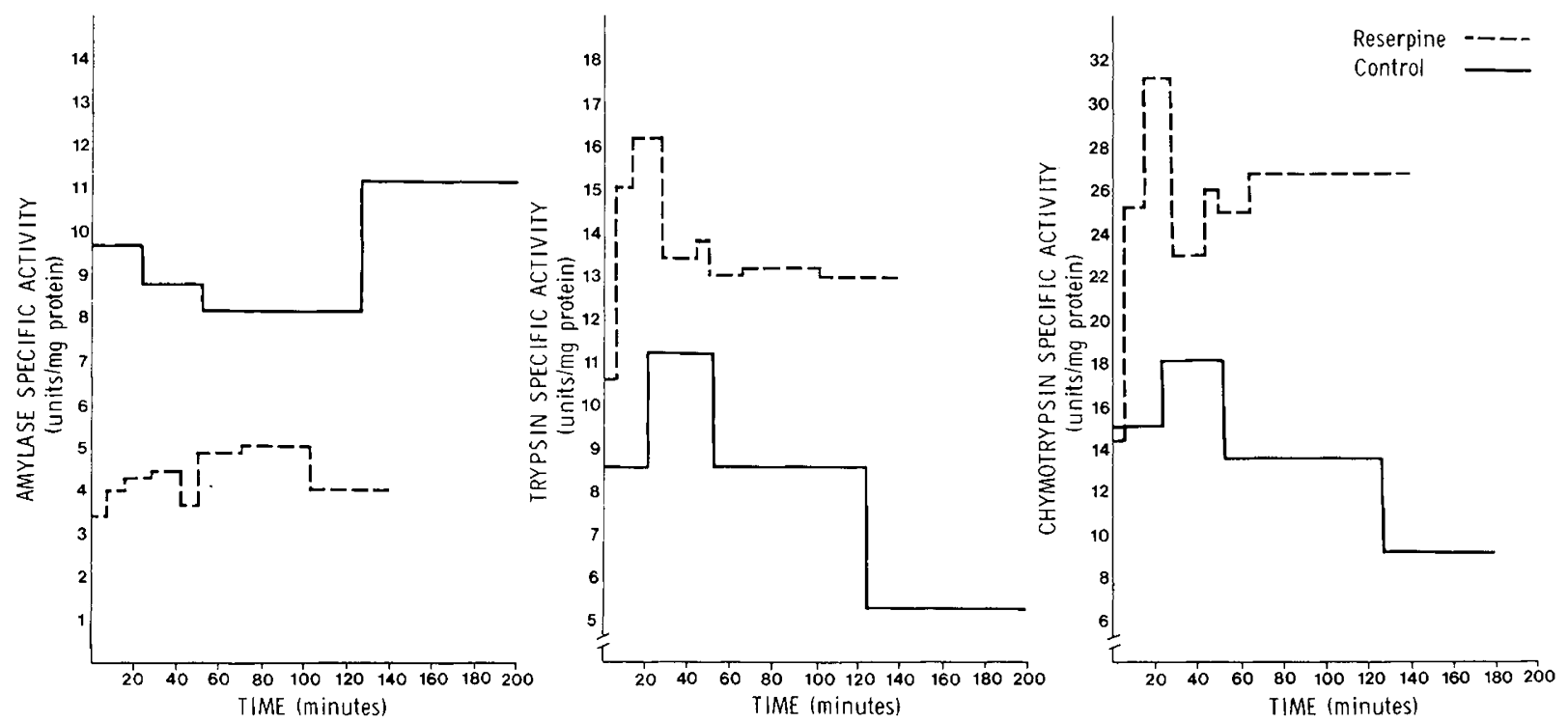

Fig. 2. Specific activities of amylase, trypsin, and chymotrypsin in the pancreatic juice of control and reserpine-treated rat after stimulation with CCK-octapeptide $(0.1 \mu \mathrm{g} / \mathrm{kg}$ body weight IV $)$. Representative experiment from a group of similar protocols.

of all three enzymes had increased in granules isolated from the pancreas of control rats when compared to those of granules isolated from nonstimulated tissue of the same animals (Table 2). In granules isolated from reserpine-treated rats, however, the specific activity of chymotrypsin was lower than in granules obtained from tissue of the same animals not subject to stimulation. Stimulation with the octapeptide of CCK caused a reduction in the specific activities of the three enzymes in granules isolated from the pancreas of control rats $1 \mathrm{hr}$ after the hormone stimulus, when compared to those obtained in granules isolated in resting tissue from similar untreated control rats (Table 2). The same was true in granules obtained from reserpine-treated rats (Table 2).

\section{ISOLATED ZYMOGEN GRANULES-ULTRASTRUCTURE}

Zymogen granules isolated from the resting (unstimulated) pancreas of control rats showed a fairly uniform electron density when studied ultrastructurally (Fig. 3). The granule preparation was essentially free of contaminating material from other intracellular organelles or membranes and the granules were delineated by well-defined membranes (Figs. 4 and 5). Granules isolated from the resting pancreas of reserpine-treated rats had several ultrastructural alterations when compared to the control ones. They seemed to have a reduced electron density and less distinct limiting membranes (Fig. 6). Several granule configurations showing a denser core and a more lucent outer rim were observed (Fig. 6). Other granules had a trizonal appearance, and a few appeared to be in the process of rupturing, showing breaks in the limiting membrane and the presence of finely granular material, presumably derived from the granular contents, lining the surface of the granules (Figs. 6 to 8 ). Some granules, however, appeared normal, with unbroken limiting membranes and uniform density of contents.

\section{DISCUSSION}

The chronic administration of reserpine to albino rats has been previously shown to inhibit the secretion of fluid and of bicarbonate from the exocrine pancreas $(10,11)$. The results of this study indicate that the drug treatment also alters the secretion of pan- 
Table 1. Total enzyme output in pancreatic juice

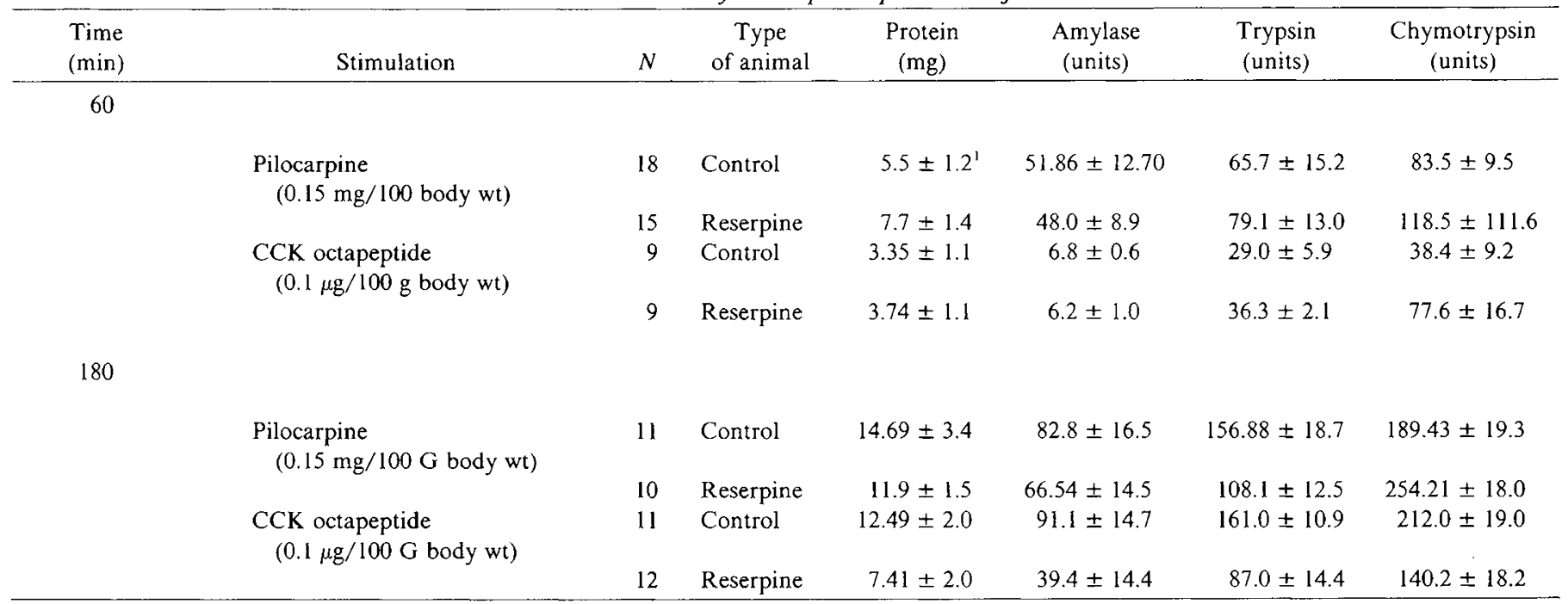

'Mean \pm S.D.

Table 2. Enzyme specific activities in isolated pancreatic zymogen granules

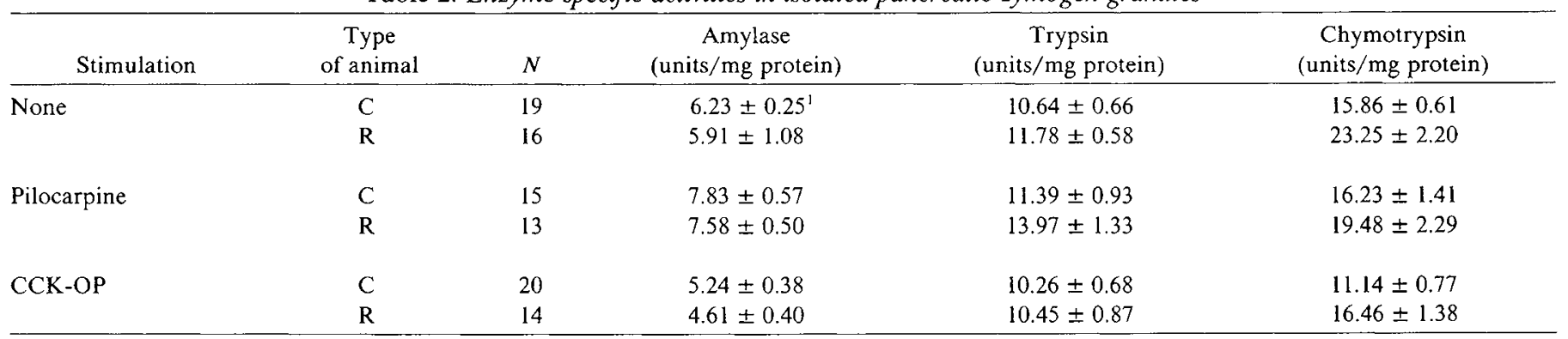

${ }^{\mathrm{I}}$ Mean \pm S.D.

creatic enzymes induced by either pilocarpine or the secretagogue hormone CCK. This effect involves several alterations: (1) an increased specific activity and total output of proteases, particularly of chymotrypsin; (2) a reduced specific activity and total output of amylase; (3) an increased output of protein during the first 60 minutes of the secretory response, most likely due to the enhanced output of proteases, but a reduced overall protein output over a longer $(3 \mathrm{hr})$ secretory period. There is, therefore, a biphasic response from the exocrine pancreas of the treated animals, which involves a rapid, enhanced release of proteases during the initial phase of this response, which is not sustained thereafter. Inasmuch as there is also a reduced fluid release, these findings suggest that pretreatment with reserpine affects the mechanisms responsible for fluid and protein secretion in pancreatic acinar cells $(10,11)$.

These alterations in the secretion of pancreatic enzymes induced by reserpine administration are related to changes in the storage of these enzymes induced by the drug treatment. Zymogen granules isolated from the pancreas of the treated animals had an increased content (expressed as specific activity) of the proteases trypsin and chymotrypsin. Because the amylase content is not increased in the granules of the treated animals, the protease/ amylase activity ratios are higher than in granules obtained from control tissue. These alterations suggest that reserpine may affect either the biosynthesis or the intracellular transport of pancreatic enzymes and that it favors the storage of proteases in the secretory granules. This dissociation is then reflected along the secretory pathway and results in the altered enzyme activities observed in the juice of the treated rats. Evidence has been presented previously that trophic hormones like CCK cause nonparallel variations in the rate of biosynthesis of pancreatic enzymes within $60 \mathrm{~min}$ of the stimulus (1). An altered turnover rate or changes in the stability of the enzymes within the secretory granules could also explain the observations reported here.

The effects of reserpine on pancreatic acinar cell function are likely to be more complex, however. In addition to nonparallel storage of enzymes in the resting state, the mechanism of exocytosis itself is also disturbed, as suggested by previous ultratructural findings (12) and by the reduced output of enzymes during a 2- to 3-hr period of secretion. A drug-induced alteration in exocytosis may explain the accumulation of secretory granules and the alterations in rough endoplasmic reticulum and Golgi membranes that occur in the pancreatic acinar cells of the treated animals (12). It remains to be seen whether a defect in exocytosis can, by itself, alter the synthetic rates of the different enzymes in a nonparallel fashion, but it appears from the ultrastructural observations on the isolated zymogen granules (this study) that the accumulation of granules with an increased protease content may lead to intracellular activation of these enzymes and to progressive granule breakdown. This may explain the increased autophagic activity observed in a previous study (12). The effects of reserpine on pancreatic acinar cells are likely to involve, therefore, a generalized disturbance in the cellular membranes concerned with the synthesis, intracellular transport and secretion of digestive enzymes.

We have shown that chronic reserpine administration results in widespread exocrine gland alterations which resemble those of patients with cystic fibrosis $(5-8,11,13,14)$. Although pancreatic atrophy and fibrosis are prominent features of this disease (2), the pathogenesis of this lesion is unknown. Hadorn et al. (3) suggested that, in functional terms, this lesion involved a decreased secretion 


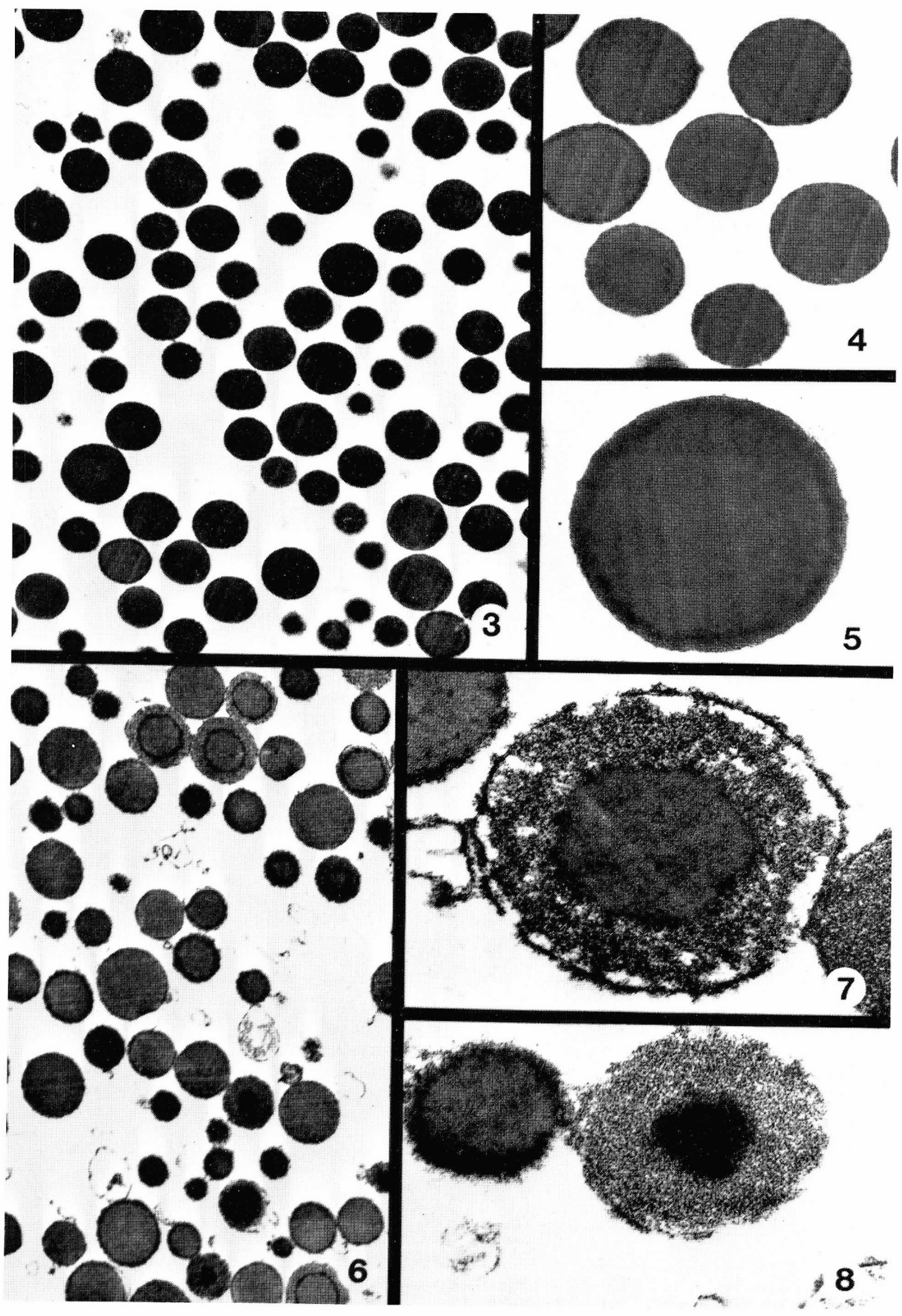


of the fluid/electrolyte fraction of pancreatic juice, either alone or in combination with an increased secretion of the macromolecular (enzyme) fraction. The present results suggest that a similar functional disturbance occurs in the pancreas of the reserpine model, involving a reduced fluid secretion and alterations in the secretion of enzymes. By analogy, our results also suggest a possible mechanism for the development of the pancreatic lesion in cystic fibrosis. An accumulation of proteases cold lead to intracellular activation of these enzymes and to progressive autodigestion of the exocrine pancreas, leading to the known pathologic findings of cyst formation, atrophy and fibrosis.

\section{CONCLUSION}

Pretreatment with reserpine alters the in vivo secretion of fluid and of digestive enzymes from the rat pancreas in response to either pilocarpine or CCK stimulation. An initial period of enhanced secretion is followed by a markedly inhibited reponse. In the first phase, lasting approximately $1 \mathrm{hr}$, the output of trypsin and chymotrypsin are increased in the juice of the treated animals. However, protein and enzyme outputs are significantly smaller in these animals when measured for $3 \mathrm{hr}$ after stimulation. Zymogen granules isolated in the resting (unstimulated) state from the pancreas of the treated animals have increased specific activities of trypsin and chymotrypsin. The granules isolated from the pancreas of reserpine-treated rats also show ultrastructural changes, including alterations in density, membrane lysis, and granule breakdown. It is concluded that reserpine administration alters pancreatic acinar cell function in the rat. This effect involves the inhibition of transepithelial fluid transport and the induction of nonparallelism in the secretion of digestive enzymes. The latter results from a drug effect on protein synthesis or intracellular transport, which causes an increased storage of proteases. Activation of the accumulated proteases inside the acinar cells is suggested by the ultrastructure of the granules isolated from the pancreas of the treated animals and may explain the development of the exocrine pancreatic pathology characteristic of cystic fibrosis.

\section{REFERENCES AND NOTES}

1. Dagorn, J. C., and Mongeau, R.: Different action of hormonal stimulation on the biosynthesis of three pancreatic enzymes. Biochem. Biophys. Acta, 498: 76
(1977).

2. Di Sant'Agnese, P. A., and Talanio, R. C.: Pathogenesis and physiopathology of cystic fibrosis of the pancreas. N. Engl. J. Med., 277: 1287, 1343, 1399 (1967).

3. Hadorn, B., Johansen, P. G., and Anderson, C. M.: Exocrine pancreatic function in cystic fibrosis. In: D. Lawson: Proceedings of the Fifth International Cystic Fibrosis Conference. pp. 55-67 (Churchill College, Cambridge, 1969).

4. Lowry, O. H., Rosebrough, N. F., Farr, A. L., and Randall, R. J. Protein measurement with the Folin phenol reagent. J. Biol. Chem., 193: 265. (1961)

5. Martinez, J. R., Adelstein, E., Quissell, D. O., and Barbero, G. J.: The chronically reserpinized rat as a possible model for cystic fibrosis: I. Submaxillary gland morphology and ultrastructure. Pediatr. Res., 9: 463 (1975).

6. Martinez, J. R. Adshead, P. C., Quissell, D O and Barbero, G. J. The chronically reserpinized rat as a possible model for cystic fibrosis. II. Composition and cilioinhibitory effects of submaxillary saliva. Pediatr. Res., 9: 470 (1975).

7. Martinez, J. R., Braddock, M. E., Martinez, A. M., and Cooper, C.: Effect of chronic reserpine administration $\mathrm{K}^{+}$and amylase release from the rat parotid gland. Pediatr. Res.. 13: 1024 (1979).

8. Mawhinney, T. P., Feather, M. S., Martinez, J. R., and Barbero, G. J.: The chronically reserpinized rat as an animal model for cystic fibrosis. I. Acute effect of isoproterenol and pilocarpine upon pulmonary lavage fluid. Pediatr. Res., 13: 760 (1979).

9. Meldolesi, J., Jamieson, J. D. and Palade, G. E. Composition of cellular membranes in the pancreas of the guinea pig. J. Cell Biol.. 49: 109 (1971).

10. Morton. D., Parker, A., Estrada, P., and Martinez, J. R.: Exocrine pancreatic secretion in rats treated with reserpine following stimulation with pilocarpine, dopamine, and caerulein. Pediatr. Res., 14: 18 (1980).

11. Perlmutter, J., and Martinez. J. R.: The chronically reserpinized rat as a possible model for cystic fibrosis: VII. Alterations in the secretory response to cholecystokinin and to secretin from the pancreas in vivo. Pediatr. Res., 12: 188 (1978)

12. Setser, M. E., Spicer, S. S., Simson, J. A. V., Adamson, M., and Martinez, J. R.: The effect of reserpine on the ultrastructure and secretory responses of rat exocrine pancreas. Exp. Mol. Pathol., 31, 413 (1979).

13. Simson, J. A. V.. Spicer, S. S., Setser, M. E.. and Martinez, J. R.: Histochemistry and ultrastructure of rat submandibular acinar cells: effects of chronic reserpine on secretion. Lab. Invest.. 39: 157 (1978).

14. Thompson, F. E.. Quissell. D. O., Williams, C. H. and Martinez, J. R. The chronically reserpinized rat as a possible model for cystic fibrosis. IV. The protein composition of pulmonary lavage fluid. Pediatr. Res., 10: 632 (1976).

15. Ruth McCurdy received a National Foundation Scholarship during the course of this work.

16. The authors express their appreciation to Mark Smith for his technical help in the ultratructural studies.

17. Requests for reprints should be addressed to: Dr. J. R. Martinez, Department of Child Health. University of Missouri School of Medicine. Columbia, MO 65212 (USA)

18. This research was supported by grant AM18150 from the National Institutes of Health. USPHS.

19. Received for publication January 21, 1981.

20. Accepted for publication March 16, 1981

Fig. 3. Isolated pancreatic zymogen granules from the unstimulated pancreas of a control rat. Constant density and variations in granular size are evident. Magnification, $\times 4300$.

Fig. 4. Intermediate power view of isolated zymogen granules from control rats. Granules have uniform density and well-defined limiting membranes. Magnification, $\times 10,000$.

Fig. 5. Higher power view $(\times 20,000)$ of a pancreatic zymogen granule from a control rat. Limiting membrane appears intact.

Fig. 6. Isolated zymogen granules from the unstimulated pancreas of a reserpine-treated rat. Variations in granular size and electron density are apparent. Granules with a bizonal configuration are seen, with a dense core surrounded by a lighter outer rim. Other granules have three density zones and breaks in the limiting membrane. Magnification, $\times 4300$.

Figs. 7 and 8 . Higher power views of zymogen granules from the pancreas of reserpine-treated rats. The granule in Figure 7 has a denser core surrounded by a granular, lighter rim and shows breaks in the limiting membrane. The granule on the right in Figure 8 shows a bizonal density, with a dense core surrounded by a lighter outer rim. No limiting membrane is clearly discernible. A smaller, denser granule on the left also seems to be undergoing lysis. Magnifications, $\times 10,000$ (Fig. 7), $\times 20,000$ (Fig. 8). 